This is a self-archived version of an original article. This version may differ from the original in pagination and typographic details.

Author(s): Laapotti, Tomi; Mikkola, Leena

Title: Social interaction in management group meetings : a case study of Finnish hospital

Year: 2016

Version: Accepted version (Final draft)

Copyright: @ 2016 Emerald

Rights: In Copyright

Rights url: http://rightsstatements.org/page//nC/1.0/?language=en

Please cite the original version:

Laapotti, T., \& Mikkola, L. (2016). Social interaction in management group meetings : a case study of Finnish hospital. Journal of Health Organization and Management, 30(4), 613-629. https://doi.org/10.1108/JHOM-02-2015-0040 


\section{Social interaction in management group meetings: a case study of Finnish hospital}

Tomi Laapotti and Leena Mikkola

Department of Communication, University of Jyväskylä, Jyväskylä, Finland 


\section{Abstract}

Purpose - The purpose of this paper is to understand the role of management group meetings (MGMs) in hospital organization by examining the social interaction in these meetings.

Design/methodology/approach - This case study approaches social interaction from a structuration point of view. Social network analysis and qualitative content analysis are applied.

Findings - The findings show that MGMs are mainly forums for information sharing. Meetings are not held for problem solving or decision making, and operational coordinating is limited. Meeting interaction is very much focused on the chair, and most of the discussion takes place between the chair and one other member, not between members. The organizational structures are maintained and reproduced in the meeting interaction, and they appear to limit discussion. Meetings appear to fulfil their goals as a part of the organization's information structure and to some extent as an instrument for management. The significance of the relational side of MGMs was recognized.

Research limitations/implications - The results of this study provide a basis for future research on hospital MGMs with wider datasets and other methodologies. Especially the relational role of MGMs needs more attention.

Practical implications - The goals of MGMs should be reviewed and MG members should be made aware of meeting interaction structures.

Originality/value - The paper provides new knowledge about interaction networks in hospital MGMs, and describes the complexity of the importance of MGMs for hospitals.

Keywords - Hospital management, Qualitative research, Meetings, Social interaction, Management groups

Paper type - Case Study 


\section{Background}

\section{Introduction}

Meetings are an essential part of organizational life and in hospitals they are also an important arena where employees can communicate, share information, and make decisions about patient care (D’Adamo et al., 2012). However, until recently relatively little research has focused on meetings themselves (Allen et al., 2015). Meetings can have many purposes for organizations, such as decision making, brainstorming and information sharing (Allen et al., 2014); they involve an investment of resources (Scott et al., 2012); and they are even connected to overall job satisfaction (Rogelberg et al., 2010). Schwartzman (1989) argued that meetings should be "a topic of research in their own right" (p. 309), not just a forum for other research topics. Many studies on meetings have generated interesting findings about general group processes, but in order to understand the manifold roles of meetings for organizations, groups, and individuals, we still need to explore meetings more thoroughly (Scott et al., 2012; Schwartzman, 2015). This case study aims to examine the importance of meetings, particularly management group meetings (MGMs), for the hospital organization as a whole and for the individual participants in the meetings, by focusing on social interaction in the meetings.

\section{The aim of the study}

The aim of the study is to understand the role of MGMs in hospital administration and organization by examining the social interaction structures of the meetings. This aim is pursued by conducting a case study from two perspectives. First, the interaction network structures of MGMs are analysed. Second, MG members' perceptions of the significance of their meetings and the meeting interaction are analysed.

Research questions:

1. How are the interaction networks structured in MGMs?

2. How do MG members perceive the meaning of MGMs?

3. How do MG members perceive the social interaction in their meetings? 


\section{Theoretical framework}

Boden (1994, p. 81) argues that meetings are occasions in which organizations produce and reproduce themselves through social interaction, and in which management is made concrete.

Schwartzman (1989, p. 309) states that by focusing on meetings, research can reveal the structures of social systems and how individuals make sense of them. In hospitals, formal practices can reflect existing interactional structures or they can create the interaction norms of the organization (ledema et al., 1999). Thus, meeting interaction structures can reveal the social and organizational structures that are behind the actions of those participating in a meeting. Hospitals are seen as complex organizations and they are characterized by traditional hierarchical, specialist-based structures (Bate, 2000; Sweeney, 2005). This study is interested in these structures and their interdependence with the interaction in MGMs. The theoretical background of the study is built upon the tradition of structuration studies in small group research (Poole et al., 1985, 1996; Poole, 2013; Giddens, 1984).

Structuration here means the social processes by which a group produces and reproduces its social system through its use of rules and resources (Giddens, 1984). The focus is on the structuration processes observable in social interaction, and also on the system and structure levels behind the structuration processes. System leve/ refers to the group and the organization as social entities, and structure level refers to the rules and resources (or guidelines) that are behind group members' actions. According to the theory of structuration, group interaction is based on structures that guide and facilitate it, and at the same time group interaction defines, re-defines and maintains these structures (Poole et al., 1996). This study focuses on the structures behind people's interaction behaviour and on how these structures affect group interaction. In the hospital environment, these structures can be, for example, profession-based structures, formal and informal power structures, situational roles, norms of interaction, and actual organizational structures, such as divisions or departments. The key to understand structuration and structures is social interaction (Poole et al., 1996).

\section{Earlier studies}

So far, little is known about the social interaction in management groups (MG) in hospitals, even though such groups are an essential part of hospitals' management. MGMs are the formal arena in which the MG functions. Hospital MG studies have often focused on perceptions. For example, Shook et al. (2005) studied members' perceptions of how conflicts emerge in MGs, and both Leggat (2007) and Graham and Jack (2008) focused on members' perceptions of the meaning of leadership skills in MGs. ledema et al. (1999) applied critical discourse analysis in their observational study of interaction in formal meetings. Their study shows that meeting talk was coherent and formal in terms of taking and giving speaking turns; participants adopted 
organizational roles and long speaking turns were usual. However, in order to understand the role of the MG in hospital management, more research on actual meeting interaction is needed.

The outcomes of MG work have also been studied. The results of a study by Naranjo-Gil et al. (2008) showed that job-related heterogeneity in top management teams facilitates strategic change with minimal impairment of operational performance. Olson et al. (2007) found that competence-based trust heightened the positive relationship between cognitive diversity and task conflict. The study results of Parayitam (2010) suggest that competence-based trust between physicians and administrative executives is important for successful decision making. Smith et al. (2006) found that power inequality within a management team has a positive effect on performance. West and Anderson's (1996) results suggest that the composition of the team impacts strongly on the quality of team innovation, but the overall level of innovation is a result of social processes within the team.

In Finland, Viitanen et al. (2011) found that MG work connects with operational management through its functions of operational coordination and information sharing. Mikkola et al. (2014a) studied authentic interaction in a hospital MGM and their results showed that the chair participated substantially more than other members; the meeting interaction was significantly task-focused and the main functions of interaction were information sharing and opinion giving. Members' participation levels differed considerably: those in managerial positions participated much more than representatives of lower levels in the hierarchy. Laapotti and Mikkola (2015) found that the main function of meeting interaction in hospital MGMs is information sharing. Their inductive study also showed that such groups do not spend much time on information processing or operational coordination, and that there are no systematic problem-solving or decision-making functions in their meetings.

\section{Data and Methods}

All the data of this study was collected in a large regional public hospital in Central Finland, as part of a bigger research project. Management structures are very similar in Finnish hospitals, so the results can be seen as transferrable among hospitals. This particular hospital was interested in cooperating so it was decided to collect the data there.

The observation data consists of video recordings of ten MGMs: five meetings at the operational area level were recorded and five at the operational unit level. The members of the operational area $(O A) M G$ are managers of their particular unit, and the chair is also the executive director of that particular area. There is also one representative of the nursing staff. In the meetings that were the focus of this study there were from six to ten participants. In two meetings there were 
visitors talking about issues relevant to the organization as a whole. The operational unit (OU) MG members are the chair, who is also the chief physician and the director in charge of the unit, the head of department, senior nurses, and members of the nursing staff. The chair is the same person at both organizational levels. There were from six to eight participants in each meeting. There was also a secretary present at both levels. The main task of MGs in Finnish hospitals is to support the directors in their management-related tasks. Medical responsibility also entails administrative responsibility, and it is the chair of the MG (i.e. a senior clinician) who is responsible for decision making, not the group.

Both MGs have a meeting once a month. The data was collected during the autumn of 2012 and spring of 2013 . Video recording was carried out with a $360^{\circ}$ panorama camera, and one or two researchers were present at each meeting. All the members of the MGs gave their written consent to participating, and visitors gave their consent orally. The area level meetings varied in length from just under one hour to almost two hours, and the full length of the video data was 7 hours 44 minutes. The unit level meetings varied in length from 45 to 70 minutes, the full length of the video data was 4 hours 35 minutes. All data was transcribed verbatim.

Social Network Analysis. The observational data was analysed with social network analysis (SNA). SNA, which is usually used in quantitative studies but can also be used in qualitative studies (Bishop \& Waring, 2012), has been quite a popular method for organization studies in general and also for healthcare studies (Prell, 2012; Dunn and Westbrook, 2011). SNA focuses on relationships (ties or edges) defined by connections between individuals or groups (nodes) in a network (Carolan, 2014). Usually the aim is to recognize significant individual nodes, relationships or crossroads of the network (Prell, 2012). The results of SNA can be presented in the form of a sociogram, which gives a visualization of the network under study.

SNA has rarely been used to analyse small group interaction per se (Sauer and Kauffeld, 2013), and even when it has focused on small groups, the data has often been gathered via surveys or interviews (Susskind et al., 2011; Sibbald et al., 2013; Quinlan and Robertson, 2013). Using observational data, the actual interaction structures of that particular situation can be analysed.

In this study, SNA was used to describe the structures of the interaction network in the MGMs. All the speaking turns were coded in to a valued and directed adjacency matrix based on participants' reactions to previous speaking turns (see Sauer and Kauffeld, 2013). Visualizations of the matrices were made with Gephi-software (Bastian et al., 2009). The interaction structures of each meeting were analysed from the visualizations and matrices. The analysis was based on interpretations of the interaction network structures from the sociograms and matrices. In addition, the centralization of each network was calculated according to Freeman's (1979) definition. Centralization is a network-level measure which describes how much the network is centred on one significant node, so it can be described as "a measure of the overall group 
interaction structure" (Sauer and Kauffeld, 2013, p. 28). This centralization measure compares the meeting interaction structure under comparison with the most centralized interaction structure possible (Sauer and Kauffeld, 2013).

Interviews. The interviews were conducted to explore what importance MG members attribute to MGMs for their work, and how they perceive the interaction during meetings. The data consisted of seven interviews with MG members, all of whom were working as managers: I1 (chair in OA and OU), 12 (member in OA, OU), I3 (OU), 14 (OA), 15 (OA), 16 (OA), and 17 (OA). For anonymity reasons, in the results section each interviewee except the chair was given a number at random, different from these I-numbers, which is used when quoting their words in this article (e.g. M3). The chair also worked as the executive director of the operational area and director in charge of the operational unit. Five of the interviewees were female and two were male.

The interviews were semi-structured and focused on two main issues: 1) Management group meetings as a part of administration and management was examined with questions like "What is the meaning of MGMs?" and "What is the meaning of MGMs for management?", and 2) Interaction in the management group meetings was approached with questions like "How would you describe the atmosphere in the meetings?" and "What kind of discussions take place in the meetings?"

The length of the interviews varied between one and one and a half hours. The interviews were audio recorded and transcribed verbatim. The interviews were conducted in Finnish, but have been translated into English for this article. Qualitative content analysis was conducted using ATLAS.ti software, to keep the analysis process transparent and systematic (Friese, 2014). Firstly, all descriptions of MG work or meetings were picked out, after which the text was condensed into meaning units which were arranged according to three main themes.

\section{Results}

\section{The structure of social interaction networks}

Characteristically, the interaction in both groups (OA and $\mathrm{OU}$ ) was very much focused on the chair. Most of the discussions at both organizational levels happened between the chair and one member at a time, not between members. This means that there were a relatively small number of group level interactions in the MGMs. This can also be seen in the centralization measures, presented in Table 1. 
TABLE 1 The centralizations of the interaction networks at the meetings*

\begin{tabular}{|l|l|l|l|l|l|l|}
\hline & Meeting 1 & Meeting 2 & Meeting 3 & Meeting 4 & Meeting 5 & Mean \\
\hline Operational area & 0.83 & 0.65 & 0.76 & 0.80 & 0.71 & 0.75 \\
\hline Operational unit & 0.44 & 0.66 & 0.87 & 0.76 & 0.79 & 0.70 \\
\hline
\end{tabular}

${ }^{*}$ The closer the value is to 1.00 , the more centralized the network is.

According to the centralization measures, only meeting 1 at the unit level was not heavily centred on the chair. Still, there were some differences between the meetings, at both organizational levels. Even though the means of centralizations between the organizational levels are quite close to each other, the deviation is bigger between the meetings at the unit level. At the area level the range of the centralization measures was $0.65-0.83$ and at the unit level $0.44-0.87$. The chair was the most central member in all the meetings.

The basic network structures can be seen in the sociograms and in the adjacency matrices. In the sociograms, the thicker the arrow, the more the nodes are in interaction with each other. One example from each organizational level will be presented below; for the rest of the sociograms, see Figures 3 and 4 in the Appendix. Even though the centralization measures were quite similar between the organizational levels, there was a clear difference in the network structures. As shown in Figure 1 and Table 2, at the operational area level the network was focused on the chair, but participation was relatively evenly divided between the other members, except for the nursing staff representative M7 (see Figure 3).

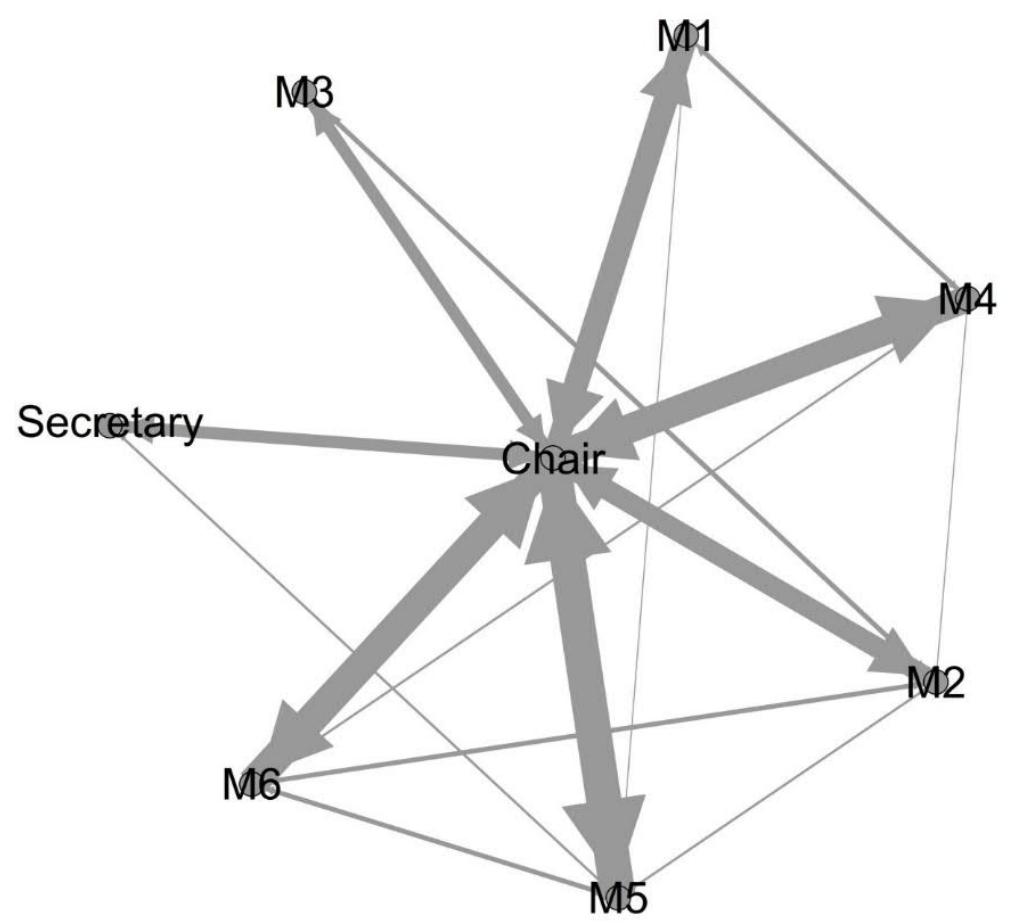

FIGURE 1 Operational area MGM 1 sociogram 
TABLE 2 Operational area MGM 1 adjacency matrix

\begin{tabular}{|l|l|l|l|l|l|l|l|l|}
\hline Area Meeting 1 & C & M1 & M2 & M3 & M4 & M5 & M6 & S \\
\hline Chair & 0 & 18 & 17 & 10 & 24 & 28 & 23 & 10 \\
\hline M1 & 20 & 0 & 0 & 0 & 3 & 0 & 0 & 0 \\
\hline M2 & 16 & 0 & 0 & 4 & 0 & 2 & 4 & 0 \\
\hline M3 & 10 & 0 & 4 & 0 & 0 & 0 & 0 & 0 \\
\hline M4 & 22 & 4 & 1 & 0 & 0 & 0 & 2 & 0 \\
\hline M5 & 29 & 1 & 1 & 0 & 0 & 0 & 3 & 2 \\
\hline M6 & 25 & 0 & 3 & 0 & 0 & 4 & 0 & 0 \\
\hline Secretary & 10 & 0 & 0 & 0 & 0 & 2 & 0 & 0 \\
\hline
\end{tabular}

At the operational unit level, as presented in Figure 2 and Table 3, participation was divided more unevenly, focusing mainly on those members who work in managerial positions (Chair, M2, and M4). On both levels, there was little interaction between members.

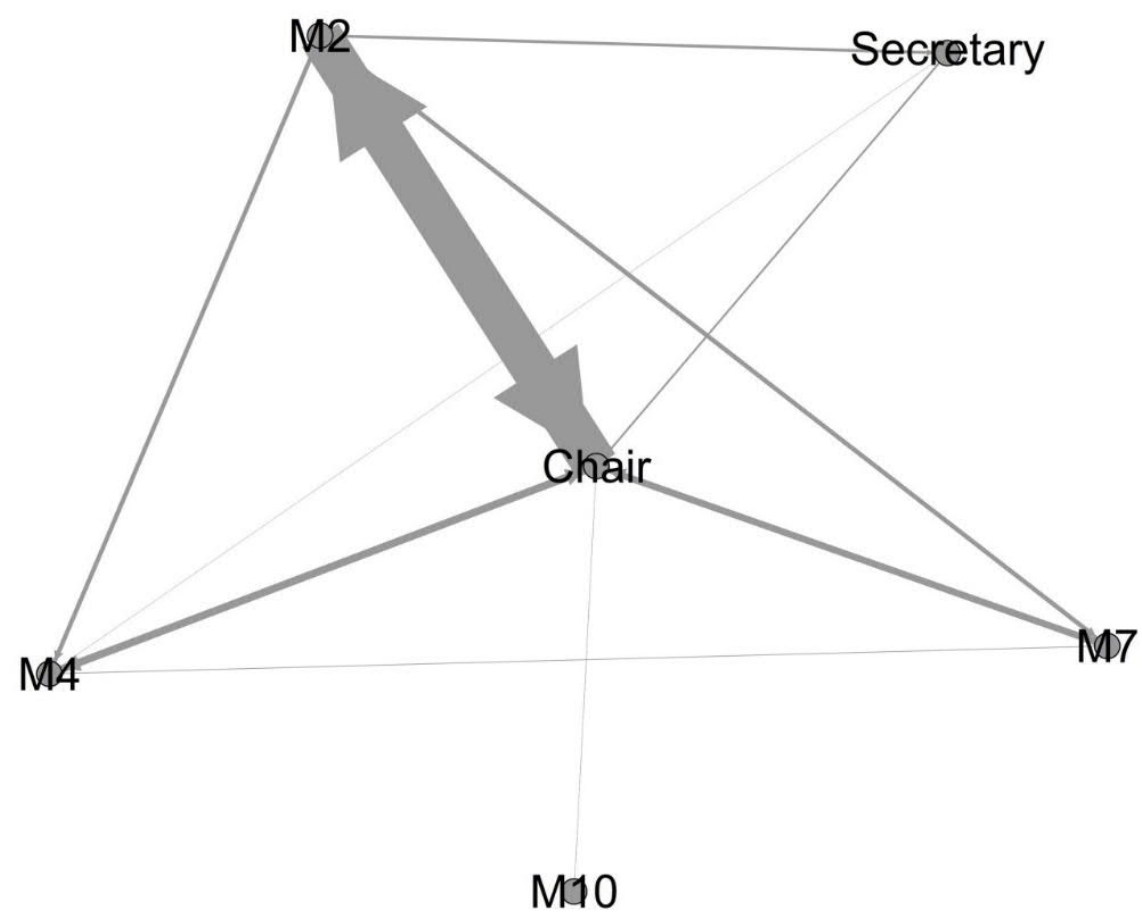

FIGURE 2 Operational unit MGM 4 sociogram

TABLE 3 Operational unit MGM 4 adjacency matrix

\begin{tabular}{|l|l|l|l|l|l|l|}
\hline Unit Meeting 4 & C & M2 & M4 & M7 & M10 & S \\
\hline Chair & 0 & 178 & 30 & 20 & 1 & 5 \\
\hline M2 & 170 & 0 & 17 & 18 & 0 & 12 \\
\hline M4 & 30 & 17 & 0 & 3 & 0 & 0 \\
\hline M7 & 27 & 12 & 2 & 0 & 0 & 0 \\
\hline M10 & 1 & 0 & 0 & 0 & 0 & 0 \\
\hline Secretary & 8 & 8 & 1 & 0 & 0 & 0 \\
\hline
\end{tabular}

Meeting 3 at the unit level was a special case; the usual chair was not present and one of the senior nurses was selected as chair for that meeting. The acting chair was the most central node of the network, but the network was very much centred on the acting chair and the head of 
department (who is a physician). The two basically talked to each other throughout the meeting (see Figure 4).

\section{The perceived meaning of management group meetings}

Task of the meetings. MG members could go some way to describing the task of the meetings, but their descriptions were quite general. Some members said that the task of the meetings was quite vague. MGMs were described first of all as informative, as important crossroads of information flows both upwards and downwards in the organizational structure. The informative nature of the meetings was also criticized on the ground that some of the information could be found elsewhere. The chair considered the main purpose of the meetings to be information sharing, basically transmitting the ideas of the health district MG (the highest level MG in the organization) to the directors of units, and arguing for any directions that are given. The chair emphasized that if there were any real problems in the units she/he had already heard of them, so the meetings were not an occasion for problem solving. Operational coordination was not seen as an important goal of the meetings and it was mentioned as something that would be processed privately or in one's own department.

Interviewer: What is the task of the MG?

M3: That is a tough question [laughs]... Well... I guess I have never seen what the task is, but if I think about what we do in these meetings, we... Everyone reports about their own unit's issues, and then the executive director of the operational area tells us about the organization's management group meeting --So it is a lot of information. And then you can put it in relation to your own operational unit, and think about what this is all about, and if you need to do anything and how...

MG members also saw the importance of the relational side of the meeting situation.

M4: I think it tells you what everyone else is doing at the moment... --- And it kind of creates a feeling of togetherness, when you know that everyone has their good and bad moments. --- You can tell the others how you are and hear how they are doing. I think it adds cohesion. --- At least you can say how you are and someone is listening [laughs].

Meetings and management work. MGMs were considered to be important for MG members' own work. In the opinion of the chair, the most important meeting was the MGM of the health district, because at the area level important issues were always dealt with outside official meetings. For members, the main value of MGMs in terms of management and administrative work was information sharing. The goals of the information sharing were usually described as purely informative, not instrumental, and members talked about "the big picture" and "guidelines". Networking that happened in MGMs was also mentioned. However, members found it difficult to describe any concrete added value that the meetings contributed to their management work. The chair thought that the MG did share good practices among its members, but that this usually happened outside the actual meeting. 
M4: --- I think it [the main task] is information sharing in all directions. And that the operational area and its units stay kind of... or that everyone knows which way the ship is going. Sort of, to know where we are going and so that we are all going in approximately the same direction. Or so that at least the goals are shared. And that we know what is happening elsewhere [in the organization] and where we are aiming and... Yes, it is like a node of information flow.

MG members did not find that their meetings offered any direct support to management at the operational level. Also, the chair considered that the instructions given in meetings were quite general. Altogether the relationship between MGMs and one's own management work was seen as being somewhat difficult to pin down, even though meetings were described as important. The value of the meetings for management was seen as moderate. As a senior nurse describes it:

NM2: Actually there is none [value for management], except that you can forward the papers... --- ...so that they are a place to make announcements in a way, in many ways. So... you cannot influence anything in those meetings.

When asked where the most important social interaction took place for administrative work, no one mentioned meetings. Interaction via e-mails and informal ways were considered to be the most important and one member even said "e-mails... --- and after the meetings". The group's powerlessness in decision making was mentioned as one reason for this.

\section{Perceived social interaction in management group meetings}

Interaction atmosphere. The overall atmosphere of the meetings was described as good, informal, and pleasant. The reasons offered for the good atmosphere were the informal style of the chair and the composition of the group. The discussion during meetings was seen as free and open and everyone was happy with the situation. Members saw no limitations to their discussion, or any themes that were excluded from discussion in the meetings.

M2: I don't think there are any taboos. --- The discussions are open and free, with no limitations.--- There is a very good atmosphere for discussion in the meetings.

M4: I think it is the people in the group. Everyone gets along and is direct with each other. And the chair is not authoritative at all; I mean he is not above anyone. It is equal... maybe like a meeting of peers.

Members considered MGMs to be a good place to talk about many issues, and they thought that group level discussions do happen in the meetings. However, some members thought there could be more discussion. The relational dimension of group level discussion and peer support for administrative issues, if needed, was also mentioned. It was also stated that there was not very much discussion about the actual items on the agenda, but discussion was rather about other topical issues about which everyone had their own opinion. 
Formality. The concept of formality was described in various ways. One senior nurse, for example, made a distinction between the two organizational levels:

NM1: Yes, you also have to act formally in this organization. --- It starts outside this unit, this formality. --When you go to operational area [meetings], they are different. --- The personalities are not personalities anymore. --- On higher organizational levels, it is all about face saving.

Another nurse manager felt that there was some hierarchy-based formality in meetings at the unit level, even though everyone had a chance to participate in the operational unit MGMs. Thus, the formality took some other form than a restriction on participation. The chair saw meetings as informal because there were no changes in the atmosphere when the meeting started, was in progress, or ended. Formality was also described as keeping the discussion within the limits of the meeting agenda.

\section{Discussion}

The main findings of the study suggest, firstly, that hierarchies and divisional differences arising out of the organizational structures are visible in the interaction structures of the MGMs, and secondly, that the importance of the meetings for the organization is complex and difficult for participants to describe. The findings will be discussed below, first from the point of view of interaction networks and then from the point of view of participant perceptions.

Interaction networks. The interaction network structures revealed that the meeting interaction reflects the organizational roles of the participants. This is in line with earlier studies.

Schwartzman (1989) and Boden (1994) described meetings as events in which the organization is made visible. ledema et al. (1999) and Atwal and Caldwell (2005) found that organizational roles have a visible effect on interaction in formal situations in health organizations. This could be seen in the interaction network structures of the meetings; organizational roles and the borderlines between different units are visible in the networks, and they appear to limit group discussion.

The interaction networks also revealed that the chair is the central figure in meetings. The importance of the chair has been established in previous studies concerning hospitals or other organizations (Asmuß and Svennevig, 2009; Mikkola et al., 2014a), but this study revealed the strong dyadic nature of discussion during meetings. The tasks that the groups are given - to assist the chair with management tasks - could explain why the chair is so central in the interaction networks, as well as the dyadic nature of the discussion. Over and above this, the organizational structures ensure that almost all administrative interdependence is dyadic between the chair and each participant, which may also strengthen the power structures deriving from the organizational structures. Becoming conscious of the interaction structures in 
MGMs would help the group to develop their interaction, and this would, for example, encourage them to share good practices across units.

In meetings at both levels, the task of the group is the same and the chair is the same person, but the interaction network structure is different. There are also differences between the meetings themselves. These results suggest that in the end the network structure is defined not only by formal organizational roles or structures but also by the social interaction in the meeting situation. At the same time, however, the results show that formal organizational roles are quite strongly visible in the networks, so they are maintained in interaction; formal structures guide the meeting interaction but do not determine it. Thus, the interaction network structures reveal the interdependence between the meeting situation and the organization as a whole, as structuration theory (Poole et al., 1996) suggests. The constantly structuring or dynamic nature of the interdependence is visible in the results in the form of transforming networks.

The difference in the interaction networks between individual meetings is an interesting finding, for the very reason that the agenda is basically identical in every meeting. From the point of view of structuration theory, this suggests that the chair and the group can decide (whether consciously or subconsciously) in interaction how the rules and resources guiding meeting interactions are perceived and executed. Thus, the meeting interaction is constantly in the process of structuration (Poole et al., 1996). One reason for this is the visitors and the constantly changing composition of the group (Dunn and Westbrook, 2011). A wider data set would perhaps tell us more about the trends in the changing networks, which is a challenge for future research.

The networks imply that the organization could face challenges in its horizontal information sharing, because of the seemingly strong boundaries between units and the hierarchical structures. Nevertheless, this study has not focused on the topics of meetings or on micro-level meeting interactions. It may be that at the operational unit level the issues discussed in meetings do not concern the staff or clinical work, but only managers and administrative work. If meetings are only a forum for the sharing of administrative information and administrative and clinical work are clearly divided (ledema, 2005), and if the nursing staff representatives do not have any actual administrative roles or responsibilities (except to be a member of the MG), then it is no surprise that they do not participate in the discussion, because they do not relate to it. If this is the case, then the organization could reconsider the goals of meetings or the composition of the groups.

Management group members' perceptions of the meetings. The nature of the meetings is informative. The way MG members talk about information and information flows reveals the idea of information as something that is transferred in interaction, or almost as something that is simply passed on to someone. After that the information is remembered and applied if needed. 
There was no talk about information processing or evaluating, so the information is not built into knowledge through interaction (Laapotti and Mikkola, 2015). However, the discussions were thought to be open, with no restrictions, and some members found that they did indeed discuss things. This implies that they have a sense of potential agency for discussion, but for some reason they do not use their agency. Thus, it seems that MG members do not see their meetings as an arena for constructing shared meanings (problem solving, evaluating information, developing their operations etc.) in group interaction.

There seem to be few actual operational or practical advantages of the meetings for management. It is probable that some of the information shared will be used as a guideline for some strategic or operational action, even though it is not explicitly processed as operational organization during meetings. MG members consider that the principle value of the information sharing that takes place in their meetings is getting the bigger picture. Members find these meetings quite important for themselves, but perhaps not for their everyday work as managers. Thus, the meaning of the meetings lies elsewhere than in achieving any of the actual goals for the meetings mentioned in the administrative rules and regulations.

As far as the relational dimension of meetings is concerned, what emerged in the interviews was a sense of community, a pleasant atmosphere, and friendly people. Also the expression "getting the big picture" implies something relational, as Schwartzman (1989) theorizes that meetings are situations where individuals position themselves as a part of the organization. Being a part of a MG can position one as a manager, which can be seen as a meaningful part of one's organizational identity. The results imply that the deeper significance of meetings is in the belongingness, identification, and participation in the process through which the organization is organized (Schwartzman, 1989; Boden, 1994). Peck et al. (2004) studied board meetings as rituals and they concluded that even if the group does not achieve the given goals, meetings are experienced as important because of their ritualistic characteristics.

The MG members' perceptions of formality were divided and somewhat vague; even though the atmosphere in meetings was described as informal, it was recognized that the meeting interaction was formal. It is somehow surprising that the interviewees could distinguish between the two. It could be that the interviewees are not familiar with idea of verbalizing concepts of social interaction, and therefore their descriptions were vague at times. Still, both of the nurses in managerial positions who were interviewed felt that the level of formality increased outside their operational unit. This suggests that the hierarchical structures are more evident to those who have a lower position in the organization's hierarchy. There is some evidence of differences in the perceived quality of teamwork between nurses and physicians in clinical work (Thomas et al., 2003), but more research is needed before one could come to any definite conclusion about the perceived hierarchy of different organizational positions. 
MGMs were described as important, but there was quite a lot of diversity and sometimes even contradictions in the members' perceptions of them. This could be due to overall vagueness in perceptions about the tasks of MGs. It could be that meetings are taken so much for granted as a part of one's work that it is difficult to really analyse their meaning or purpose. Also the specializations of each member differ to a greater or lesser extent, and this might have had some influence on their perceptions.

Implications for future research. This case study provides new knowledge about interaction networks in hospital MGMs, and describes the complexity of the meaning of MGMs for hospitals. To some extent the conclusions of this study can be transferred (Lincoln and Guba, 1985) to other organizations, at least to other hospitals and organizations in which MGs do not have explicit administrative responsibilities. This is because meetings are ubiquitous in society and they have been found to be quite similar across contexts, goals, and cultures (Schwartzman, 1989). The results of this study provide a basis for future research and underline the importance of the institution called a meeting. More research is needed to study how organizational structures affect meeting interaction structures in different organizations and contexts. Also the relational meaning of meetings needs more research attention. If we focus only on the task dimension of meetings, we are likely to miss something rather important (see also Peck et al., 2004). In addition, this study reinforces the importance of studying natural groups in their natural contexts. This is because both the immediate and the temporal context have an effect on group interaction, and also because the tasks given to groups differ in many ways: for example, decision making is not as prominent in group work as the research literature would indicate (Olbertz-Siitonen et al., 2014; Frey, 2003; Scheerhorn et al., 1994). Research on meetings and their meanings in different contexts still has a lot to uncover.

The importance of management group meetings. Finally, let us try to draw some conclusions about the importance of MGMs for a hospital organization and for the individuals who make up the organization. The role of meetings is twofold. Firstly, they are about achieving the tasks set for them by the hospital organization. This happens through information sharing and to some extent through operational coordination. However, it seems that tasks originally designed for the MGMs are usually carried out outside the meeting situations (e.g. because problems cannot wait for meetings) and therefore the role of the meetings has changed; it is no longer what is written down in the hospital's administrative rules. Thus secondly, and in this case perhaps more importantly, the meetings are about the relational level of organizational life, which is evident in the sense of togetherness and belonging that is brought about by being a member of an MG. MGMs also serve as a place for networking, which may break down some of the barriers between units and make it easier for people to contact each other. These two levels are interwoven. At least to some extent the relational level can enhance the hospital's administration and clinical work even more than the task level, because it is the relational level 
that can create commitment and well-being in the organization, for example by positioning MG members as part of the organization.

Limitations. Firstly, the observation data was video recorded in authentic meetings and the presence of a video camera and a researcher may have had an effect on those who participated in the meetings. In the first meetings recorded at both organizational levels the atmosphere is slightly more formal than in the following meetings; for example, sometimes when participants seek a speaking turn they are quite formal, which does not happen later. Nevertheless, this does not have a very serious effect on the interaction networks. It has been found that when observations continue, the behaviour of the research participants settles down (Frey et al., 2000), which can also be seen in this data. Secondly, the relatively small dataset must be taken into consideration, especially when comparing the centralization measures. The centralization measures were calculated only to support the qualitative analysis and interpretation of the visualized interaction networks. Thirdly, because of the aim of the study, the interviews were quite structured, which might have had an effect on the responses. This has been borne in mind when reporting the results and drawing conclusions.

\section{Acknowledgments}

An earlier version of this study was presented at the 10th Annual INGRoup Conference in Pittsburgh PA, USA, in July 2015. Similar findings concerning the dyadic nature of the meeting interaction structure were presented in an earlier publication in Finnish (Mikkola et al., 2014a). The present paper is based on the first author's doctoral dissertation under preparation, supervised by the second author. This paper has been funded by the Finnish Work Environment Fund, and part of the research project Social Interaction Practices and Well-being at Hospital Workplace (TSR112304). The first author has also received a grant from The Foundation for Municipal Development. 


\section{References}

Allen, J. A., Lehmann-Willenbrock, N. and Rogelberg, S. G. (2015), "Introduction to The Cambridge Handbook of Meeting Science. Why Now?", In Allen, J. A., LehmannWillenbrock, N. and Rogelberg, S. G. (Eds.), The Cambridge Handbook of Meeting Science, Cambridge University Press, New York, NY, pp. 3-11.

Allen, J. A., Beck, T., Scott, C. W. and Rogelberg, S. G. (2014), "Understanding workplace meetings: a qualitative taxonomy of meeting purposes", Management Research Review, Vol. 37 No. 9, pp. 791-814.

Asmuß, B. and Svennevig, J. (2009), "Meeting talk. An introduction", Journal of Business Communication, Vol. 46 No. 1, pp. 3-22.

Atwal, A. and Caldwell, K. (2005), "Do all health and social care professionals interact equally: a study of interactions in multidisciplinary teams in the United Kingdom", Scandinavian Journal of Caring Sciences, Vol. 19 No. 3, pp. 268-273.

Bastian, M., Heymann, S. and Jacomy, M. (2009), "Gephi: An open source software for exploring and manipulating networks", paper presented at International AAAI Conference on Weblogs and Social Media, May 17-20 2009, San Jose, CA, available at: http://www.aaai.org/ocs/index.php/ICWSM/09/paper/view/154/1009 (accessed 11 November 2015).

Bate, P. (2000), "Changing the culture of a hospital: from hierarchy to networked community", Public Administration, Vol. 78 No. 3, pp. 485-512.

Bishop, S. and Waring, J. (2012), "Discovering healthcare professional-practice networks: the added value of qualitative SNA", Qualitative Research in Organizations and Management: An International Journal, Vol. 7 No. 3, pp. 308-322.

Boden, D. (1994), The business of talk: Organization in action, Polity Press, Cambridge, UK.

Carolan, B. V. (2014), Social network analysis education: Theory, methods \& applications, Sage, Thousand Oaks, CA.

D'Adamo, M., Fabic, M. S. and Ohkubo, S. (2012), "Meeting the health information needs of health workers: what have we learned?", Journal of Health Communication: International Perspectives, Vol. 17 No. 1, pp. 23-29.

Dunn, A. G. and Westbrook, J. I. (2011), "Interpreting social network metrics in healthcare organisations: a review and guide to validating small networks", Social Science \& Medicine, Vol. 72 No. 7, pp. 1064-1068.

Freeman, L. C. (1979), "Centrality in social networks conceptual clarification", Social Networks, Vol. 1 No. 3, pp. 215-239.

Frey, L. R. (2003), "Introduction”, in Frey, L. R. (Ed.), Group communication in context. Studies of bona fide groups, (2nd ed.), Lawrence Erlbaum Associates, Mahwah, NJ, pp. 1-22.

Frey, L. R., Botan, H. C. and Kreps, G. L. (2000), Investigating communication. Introduction and research methods, (2nd ed.), Allyn and Bacon, Boston, MA.

Friese, S. (2014), Qualitative data analysis with ATLAS.ti, (2nd ed.), Sage, London, UK.

Giddens, A. (1984), The constitution of society, Polity Press, Cambridge, UK. 
Graham, I. W. and Jack, E. (2008), "Promoting leadership: the development of a nurse executive team in an acute hospital trust", Journal of Nursing Management, Vol. 16 No. 8, pp. 955-963.

ledema, R., Degeling, P. and White, L. (1999), "Professionalism and organisational change", in Wodak, R. and Ludwig, C. (Eds.), Challenges in a changing world. Issues in critical discourse analysis, Passagen Verlag, Wien, pp. 127-155.

ledema, R. (2005), "The tension between professional and institutional discourse: an applied linguistic analysis of hospital communication", Journal of Applied Linguistics, Vol. 2 No. 3, pp. 243-252.

Laapotti, T. and Mikkola, L. (2015), "Message functions in hospital management group meetings", [In Finnish: "Kokousvuorovaikutuksen tehtäväkeskeiset funktiot sairaalajohtoryhmässä"], Työelämän Tutkimus, Vol. 13 No. 1, pp. 38-55.

Leggat, S. G. (2007), "Effective healthcare teams require effective team members: defining teamwork competencies", BMC Health Services Research 7:17, available at: http://www.ncbi.nlm.nih.gov/pmc/articles/PMC1800844/pdf/1472-6963-7-17.pdf (accessed 23 February 2015).

Lincoln, Y. S. and Guba, E. G. (1985), Naturalistic inquiry, Sage, Newbury Park, CA.

Mikkola, L., Pennanen, E., Valkonen, T., Viitanen, E., Virtanen, J., Kokkinen, L. and Puolijoki, H. (2014a), "Social interaction in public hospital management group meetings: examining participation through the Interaction Process Analysis", [In Finnish: "Vuorovaikutus julkisen sairaalan johtoryhmäkokouksissa: Johtoryhmäjäsenten osallistumisen tarkastelua vuorovaikutuksen prosessianalyysin keinoin"], Hallinnon Tutkimus Vol. 33 No.3, pp. 211-224.

Mikkola, L., Pennanen, E., Laapotti, T. and Välipakka, H. (2014b), "Social interaction practices and well-being at hospital workplace", [In Finnish: "Sairaalatyöyhteisön työhyvinvointia rakentavat vuorovaikutuskäytänteet"], University of Jyväskylä, Jyväskylä, Finland.

Naranjo-Gil, D., Hartmann, F. and Maas, V. S. (2008), "Top management team heterogeneity, strategic change and operational performance", British Journal of Management, Vol. 19 No. 3, pp. 222-234.

Olbertz-Siitonen, M., Siitonen, M. and Valo, M. (2014), "Naturally occurring data in the study of virtual teams in working life: challenges and opportunities", in Työelämän tutkimuspäivät 2013. Työn tulevaisuus. Työelämän tutkimuspäivien konferenssijulkaisuja: 5/2014, Tampereen yliopisto, pp. 185-192, available at:

http://tampub.uta.fi/bitstream/handle/10024/95420/tyoelaman_tutkimuspaivat_2013.pdf? sequence $=1>$ (accessed 10 January 2015).

Olson, B. J., Parayitam, S. and Bao, Y. (2007), "Strategic decision making: the effects of cognitive diversity, conflict, and trust on decision outcomes", Journal of Management, Vol. 33 No. 2, pp. 196-222.

Parayitam, S. (2010), "The effect of competence-based trust between physicians and administrative executives in healthcare on decision outcomes", Management Research Review, Vol. 33 No. 2, pp. 174-191.

Peck, E., 6, P., Gulliver, P. and Towell, D. (2004), "Why do we keep on meeting like this? The board as ritual in health and social care", Health Services Management Research, Vol. 17 No. 2, pp. 100-109.

Poole, M. S., Seibold D. R. and McPhee R. D. (1985), "Group decision-making as a structurational process", Quarterly Journal of Speech, Vol. 71 No. 1, pp. 74-102. 
Poole, M. S., Seibold D. R. and McPhee R. D (1996), "The structuration of group decisions", in Hirokawa, R. Y. and Poole, M. S. (eds.), Communication and group decision making (2nd ed.), Sage, Thousand Oaks, CA, pp. 114-147.

Poole, M. S. (2013), "Structuration research on group communication", Management Communication Quarterly, Vol. 27 No. 4, pp. 607-614.

Prell, C. (2012), Social network analysis. History, theory \& methodology. Sage, Thousand Oaks, CA.

Quinlan, E. and Robertson, S. (2013), "The communicative power of nurse practitioners in multidisciplinary primary healthcare teams", Journal of the American Association of Nurse Practitioners, Vol. 25 No. 2, pp. 91-102.

Rogelberg, S.G., Allen, J. A., Shanock, L., Scott, C. and Shuffler, M. (2010), "Employee satisfaction with meetings: a contemporary facet of job satisfaction", Human Resource Management, Vol. 49 No. 2, pp. 149-172.

Sauer, N. C. and Kauffeld, S. (2013), "Meetings as networks: applying social network analysis to team interaction", Communication Methods and Measures, Vol. 7 No. 1, pp. 26-47.

Scheerhorn, D., Geist, P. and Teboul, J. C. B. (1994), "Beyond decision making in decisionmaking groups: implications of the study of group communication", in Frey, L. R. (ed.), Group communication in context: Studies of natural groups, Lawrence Erlbaum Associates, Hillsdale, NJ, pp. 247-262.

Schwartzman, H. B. (1989), The meeting. Gatherings in organizations and communities, Plenum press, New York, NY.

Schwartzman, H. B. (2015), "There's something about meetings: The order and disorder in the study of meetings." In Allen, J. A., Lehmann-Willenbrock, N. and Rogelberg, S. G. (Eds.), The Cambridge Handbook of Meeting Science, Cambridge University Press, New York, NY, pp. 735-745.

Scott, C. W., Shanock, L. R. and Rogelberg, S. G. (2012), "Meetings at work: advancing the theory and practice of meetings", Small Group Research, Vol. 43 No. 2, pp. 127-129.

Shook, C. L., Payne, G. T. and Voges, K. E. (2005), "The "what" in top management group conflict: the effects of organizational issue interpretation on conflict among hospital decision makers", Journal of Managerial Issues, Vol. 17 No. 2, pp. 162-177.

Sibbald, S. L., Wathen, C. N., Kothari, A. and Day A. M. B. (2011), "Knowledge flow and exchange in interdisciplinary primary health care teams (PHCTs): an exploratory study", Journal of the Medical Library Association, Vol. 101 No. 2, pp. 128-137.

Smith, A., Houghton, S. M., Hood, J. N. and Ryman J. A. (2006), "Power relationships among top managers: does top management team power distribution matter for organizational performance?", Journal of Business Research, Vol. 59 No. 5, pp. 622-629.

Susskind, A. M., Odom-Reed, P. R. and Viccari, A. E. (2013), "Team leaders and team members in interorganizational networks: an examination of structural holes and performance", Communication Research, Vol. 38 No. 5, pp. 613-633.

Sweeney, K. (2005), "Emergence, complexity and organisational development", In Peck, E. (Ed.), Organisational development in healthcare. Approaches, innovations, achievements, Radcliffe Publishing, Abington, pp. 143-166. 
Thomas, E. J., Sexton, J. B. and Helmreich, R. L. (2003), "Discrepant attitudes about teamwork among critical care nurses and physicians", Critical Care Medicine, Vol. 31 No. 3, pp. 956-959.

Viitanen, E., Virtanen, J. V., Kokkinen, L., Valkonen, T., Mikkola, L. and Puolijoki, H. (2011), "How effective are hospital management teams?", [In Finnish: "Sairaalan johtoryhmät kaipaavat kehittämistä"], Suomen Lääkärilehti, Vol. 66 No.5, pp. 373-377.

West, M. A. and Anderson, N. R. (1996), "Innovation in top management teams", Journal of Applied Psychology, Vol. 81 No. 6, pp. 680-693. 


\section{Appendix}

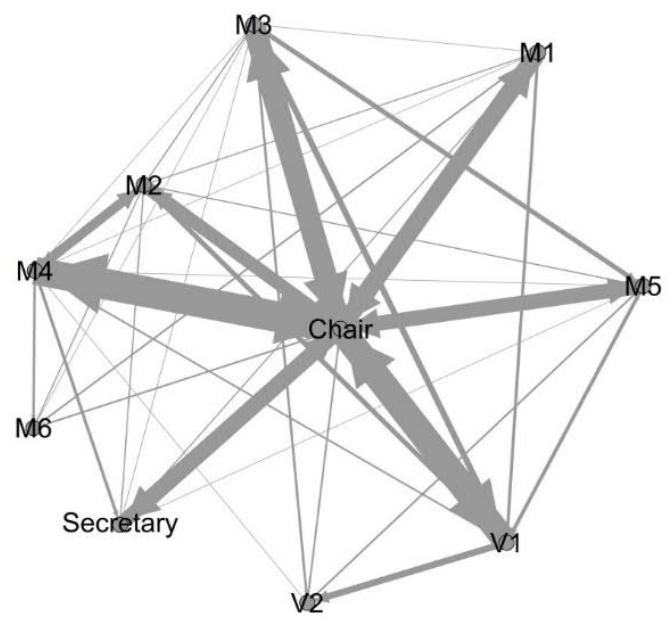

Operational area level: Meeting 2 $\mathrm{V} 1$ and V2 were visitors in this

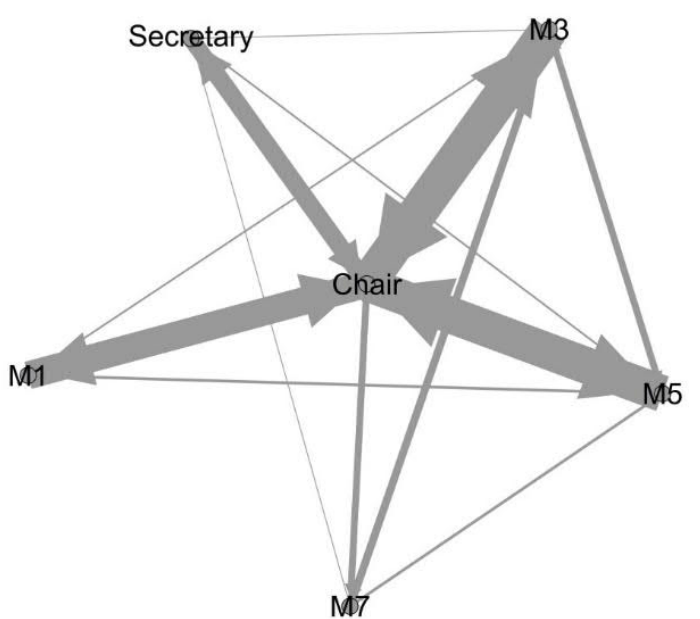

Operational area level: Meeting 3

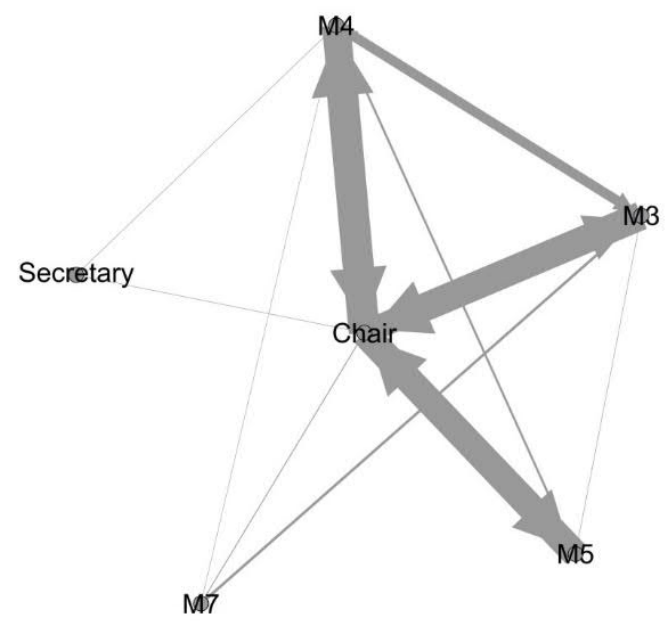

Operational area level: Meeting 4

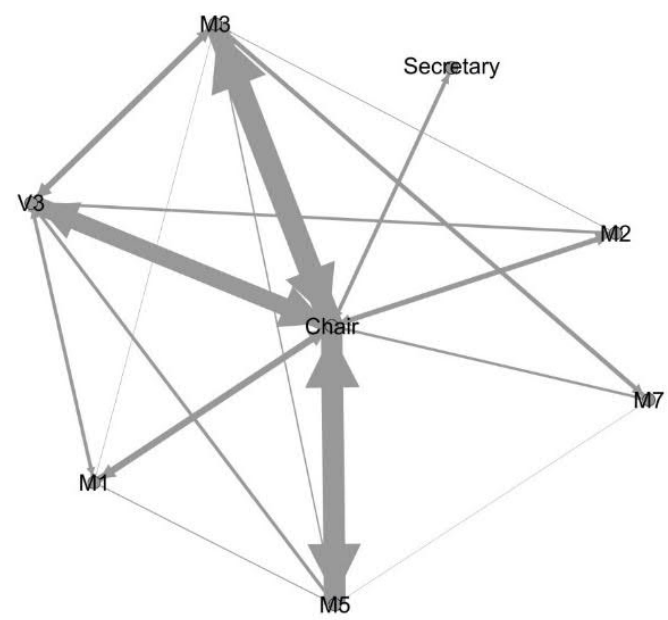

Operational area level: Meeting 5 V3 was a visitor in this meeting

FIGURE 3 Sociograms of the operational area level MGMs 


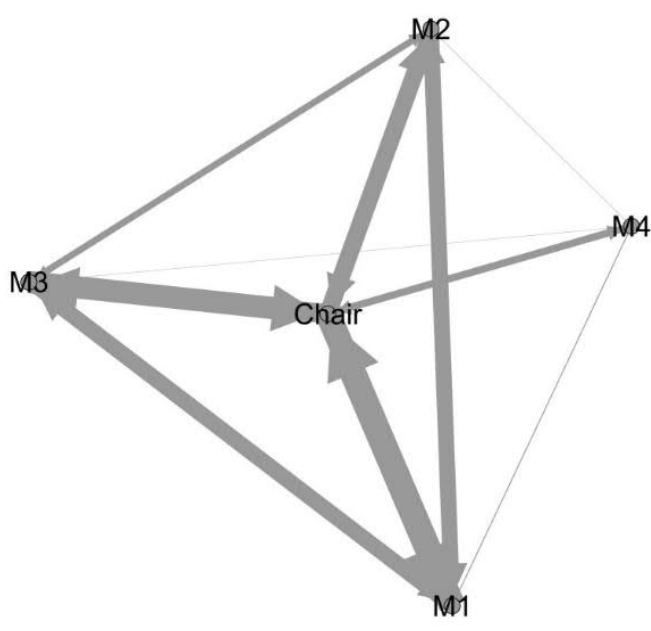

Operational unit level: Meeting 1 In managerial position: Chair, M1, M2,

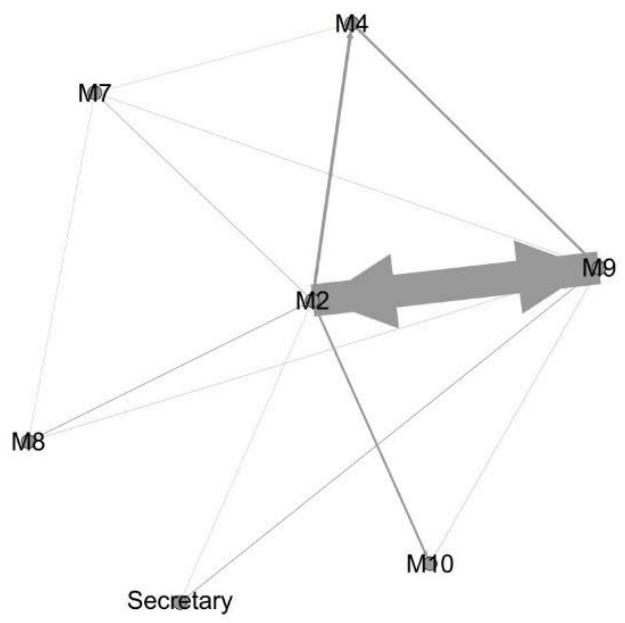

Operational unit level: Meeting 3 M2 was the chair in this meeting In managerial position: M2, M4, M9

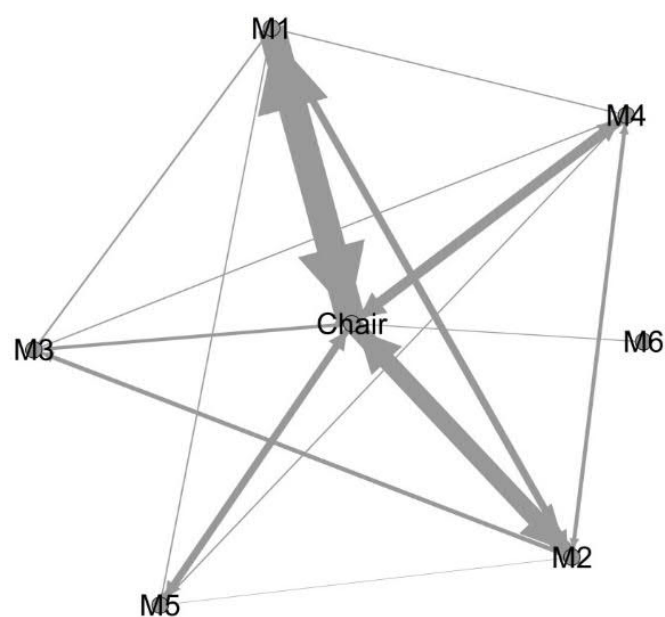

Operational unit level: Meeting 2 In managerial position: Chair, M1, M2,

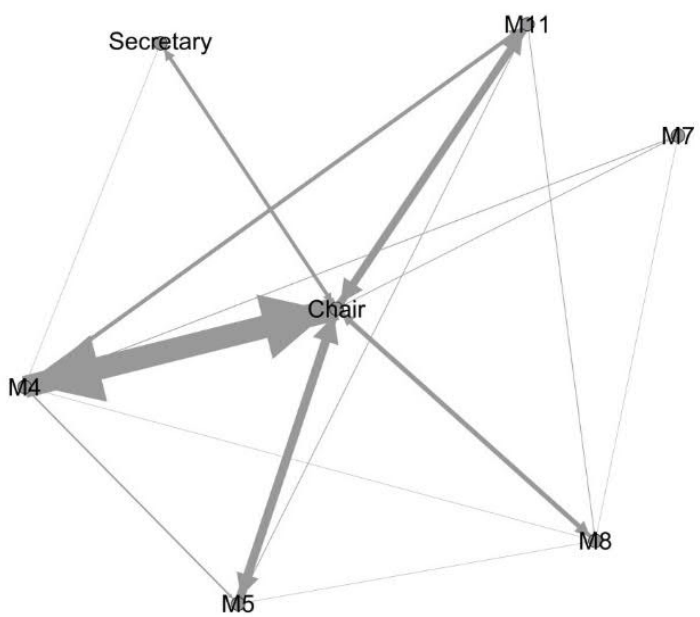

Operational unit level: Meeting 5 In managerial position: Chair, M4

FIGURE 4 Sociograms of the operational unit level MGMs

\section{About the authors}

Tomi Laapotti, MA, is a Doctoral Student in the Department of Communication, University of Jyväskylä, Finland. Tomi Laapotti is the corresponding author and can be contacted at: tomi.laapotti@jyu.fi Leena Mikkola, PhD, (the Supervisor of the dissertation) is a Senior Lecturer in the same Department. 